population of over 13,000 children. How far the inclusion of data from the remaining homes would have modified the statistics obtained it is impossible to say, but it is natural to suppose that those institutions which were best organised with respect to medical supervision would answer, while those whose arrangements were less creditable would maintain a discreet silence. Hence there is some reason to fear that reliance on the figures given in the report may lead to unduly optimistic conclusions. Even so, the council of the league is driven to the conclusion that the existing arrangements are inadequate, especially among the smaller homes. The actual figures show that of the 47 institutions which sent replies, 38, or 80.8 per cent., had salaried or honorary medical officers on their staffs, and that in 17, or 36.1 per cent., provision was made for periodical inspection apart from actual recognised illness, these latter homes containing altogether 9869 children, or over two-thirds of all those dealt with in the report. In 41 homes medical examination of the children with respect to diseases of the eye, ear, nose, throat, and teeth is carried out on admission. Records of the physical development of the children are not kept as they should be, rather less than half the institutions keeping a register of weight, and other features being even less regularly noted. One institution has its own sanatorium for incipient tuberculous patients, with an open-air school, and another has a country branch for delicate children. The whole report throws valuable light upon a matter of considerable importance, which seems hitherto to have escaped public attention, and we welcome the action of the league in instituting the inquiry. Now that the question has been raised, we hope it may be found possible to elucidate the degree of medical care under which the children live in those institutions which have not replied to the circular.

IN consequence of the death of His Majesty King Edward VII. the Conference of the Child Study Society, arranged to be held at Tunbridge Wells on May 19th, 20th, and 21st, has been postponed to June 10th and 11th.-The Council of the Edinburgh University Club of London has decided to postpone the dinner of the club already announced for May 27th until July 22nd. Sir Robert Finlay has again promised to take the chair.

THE meeting of the Society of Tropical Medicine and Hygiene fixed for Friday, May 20th, is postponed to Friday, May 27th, at 8.30 P.M.

'The Manchester Infirmary Site.-The controversy over the question, "What must be done with the Manchester infirmary site?" still rages. The Manchester city council is as far from a decisive answer to the question, apparently, as ever it was; while the suggestions that flood the local papers are almost innumerable. One group would have a new Exchange, and a conference has been held between representatives of the directors of the Royal Exchange and the Exchange Subscribers' Association, with the Infirmary Site Committee of the corporation, but for the present the negotiations have come to naught. Another group is dead against the Exchange idea, and wants an open space, as a lung, where one would be certainly useful. But while some would secure "for all time a grand open space for thousands of our city toilers to enjoy a chat and a smoke in their leisure time," others say that instead of being a beauty spot, "it would become a lounging place for tramps and outcasts." Many more cling to the idea of an art gallery and free library. Other schemes are suggested in plenty, some more grotesque than others, but none that has seized on the public mind. In the meantime the old building, with all its associations of grave and gay, has been razed to the ground, the last portion to fall being the fine $x_{\text {onic }}$ columns that adorned the entrance.

\section{THE AIMS OF MEDICAL EDUCATION} AND THE TEACHING OF THE EARLY SUBJECTS OF THE MEDICAL CURRICULUM.

(An Abstract of the Introduction to the General Report upon Medical Education Prepared at the Request of the President of the Royal College of Surgeons in Ireland and Submitted to the (jouncul of the College, Fibruary, 1910.)

\section{BY A. CAMPBelu Geddes, M.D. EdiN.,}

PROFESSOR OF ANATOMY IN THE ROYAL COLLEGE OF SURGEONS IN IRELAND

THE aim of medical education is to produce competent general practitioners, who can observe with accuracy, who can draw logical deductions from the facts observed, and who possess minds receptive of new ideas. It is not the aim of medical education to produce anatomists, physiologists, or bacteriologists; nor is it its aim to produce specialists in the various departments of medicine and surgery. Specialised scientific knowledge is rightly the product of post-graduate work.

The governing factor in the determination of all medical curricula is the time available. It may be at once admitted that the minimum period of five years is all too short for the evolution of a scientific practitioner from the raw material of the schools; but from the economic point of view a minimum of five years seems to be the practicable maximum.

During his years of study the developing practitioner not only gains nothing from his profession but has to live and to pay for his education. Fven with the five years' minimum these charges represent a considerable capital outlay, and at its end a further outlay is usually necessary as a preliminary to earning more than the barest competency. It is obvious, however, that whatever period be selected as the compulsory minimum, the average duration of the student's course must exceed it. Not even the most brilliant can obtain their qualification in a shorter time, and even they, through ill-health or as a result of domestic or financial difficulties or, deliberately, through a desire to enter more fully into the study of some one or other of the subjects of the curriculum, may take more than the minimum time to obtain their qualification. Similarly for all the less brilliant. At the other end of the scale of intellect there are men who learn slowly and cannot hope to attain to the pass standard in the time officially contemplated. There are still others who only devote a part of their day to medical study, and these cannot hope to get through in less than six or seven years. Finally, there are the idlers who do not try to acquire knowledge until parental pressure becomes extreme. Under such circumstances the average time taken by students to pass through their course of professional studies alone gives little index of the reasonability of the demands of a curriculum.

At present medical education is in a state of unstable equilibrium, for among those interested there are two parties which have tacitly assumed that the five years' curriculum is incapable of producing scientific practitioners. The one maintains that the goal of formal medical education is to endow the student with a broad outlook upon the science and art of medicine; the other, that it is to equip the student with a knowledge of the details of treatment. A course of medical education based on this latter ideal must inevitably produce practitioners whose life work will be guided by rule of thumb, whereas all courses based on that must be essentially dishonest. Surreptitiously, it seeks to extend the minimum curriculum from five years to seven or eight. If the men who receive their qualification from a licensing body can afford and have the wisdom voluntarily to continue their pupilage as resident surgeons or physicians in some general hospital, or in attendance at some specialist clinique, for a period of two or three years, they may develop into highly efficient practitioners, but only in name will they be the product of a five years' course of studies. But these are extreme views, and between them the best solution of the difficulty is to be found. It is that the schools should insist upon just so much knowledge of recognised clinical methods as will make the young graduate a tolerably safe practitioner, and that the remainder of the available time should be devoted to instilling the broad outlook. In short, the time-limit compels compromise. 
Amid the clash of vested interests a satisfactory compromise is difficult of attainment; a necessary preliminary to attempting it is to analyse the aim of medical education.

It is true that the ultimate aim is to produce competent practitioners; but the proximate aim is twofold: first, to educate minds to an understanding of the facts of life; second, to give sound, if elementary, technical training. Elementary the training must be; for the elements are essentials, and there is no time to produce universal specialists. For an examining body to strive to insist upon a detailed knowledge of the whole of medicine, surgery, and midwifery is wrong, and stultifies the whole object of education. To acquire such knowledge within the short time available demands cramming, and cramming is the curse of the medical schools. But apart from that, the most busy and successful practitioner does not carry all his available knowledge in his head. He knows in what books to look for unusual information. For this very reason every practitioner should have learned as a student how to use books. Such knowledge is the best prophylactic against premature senescence. In short, the proximate aims of medical education are:-(1) To teach a man to observe; (2) to strengthen his powers of thought and deduction; (3) to give him a broad outlook on the science of life; (4) to teach him the actual details of the treatment of injuries and emergencies and the common ailments; and (5) to teach him how to use books - the common memory of the profession.

To construct an outline of the aims of medical education is not difficult; it is not easy to solve the problems that hinder their achievement. It is a platitude that a school is made successful neither by its curriculum alone, nor by its equipment alone, but by these and the work of the men who are its teachers. But important as is the question of personnel, to obtain good anatomists, good physiologists, good pathologists as teachers is the beginning, not the end, of the problem of the teaching staff. To coördinate the work of the departments and thus to save all possible time is more difficult by far. It seems, indeed, as if what many schools lack is some coördinating authority which, through its control of the purse, has power to make its rulings operative. The composition of the controlling body must differ in different schools; but it is useless to expect the faculty to control the strong man whose energies overshadow theirs, or the scientist who is a poor teacher but whose researches are truly brilliant. If the faculty are friendlily disposed to one another, their friendship makes them lenient judges ; if they are rent by dissensions, every decision is the result of faction voting. At best the decisions of a committee are the result of compromise; and when the medical curriculum, on a five years' basis, must itself be a most carefully balanced compromise, there is no room for further compromises. One solution would be to have an individual acting as controller and coördinator. Coördination of effort is the keynote of success in commercial enterprise ; there seems no reason to suppose that coordination of effort will not make for success in the sphere of medical education; and just as men to manage, to direct, to control are needed in all large business undertakings, so they are required in all medical schools.

The duty of such a "managing director" should be to secure perfect coördination between the teaching departments, to prevent overlapping or lacunæ in the instruction of the student, to secure so far as funds permit a steady output of original work from the school's laboratories, to make provision for post-graduate courses, to lighten, so far as possible, the load of administrative work and financial responsibility which cramps and hinders the heads of all large teaching departments.

Granted that a competent staff, alive to the needs of modern education, has been secured, and granted that coördination of the departments has been provided for, it is essential to find and to adopt the best methods of educating the student and of imparting to him all requisite technical instruction. It has been hypothesised that the proximate aim of medical education is to teach a student to observe, to strengthen his powers of thought and deduction, to give him a wide outlook on the facts of life, and to make him familiar with the details of the treatment of injuries, cases of emergency, and the common ailments of mankind, and how to find any further information he may require in books. It is clear that this syllabus of training is readily divisible into two parts, the first purely educative, the second almost as purely technical. Methods suitable for imparting instruction in the educational part of the curriculum may be altogethe unsuitable when the technical portion is reached.

But this division of the aims of medical education is not the greatest difficulty that confronts him who would recommend the adoption of particular methods of instruction. The real difficulty is presented by the extraordinary differences in mental development shown by the students within the walls of one school. Not only are the natural mental powers of students vastiy different, but of a group of freshmen some are callow schoolboys, others graduates in arts, still others are well versed in chemistry, physics, and perhaps biology. Each student presents a different problem. In some cases it is necessary to educate senses; in others, minds ; and if that be once effected the subsequent technical training presents no real difficulty. But senses and minds will never be educated if students are treated as driven cattle. From the very earliest moment of their entry into the school of medicine the students shoald be, must be, if the best is to be made of them, taken as individuals and studied by their teachers. In fact, if this be faithfully done at the outset of their medical career, it matters less how they are dealt with later. The start of the curriculum is the critical part, and it is necessary that the methods adopted there should be far more elaborate and the supervision exercised far closer than is advisable in the later subjects. Whether the studies of the curriculum be regarded from the educative or from the technical point of view, they divide themselves sharply into two groups. In the first group the normal is studied; in the second the abnormal. This division is readily recognisable, and it is convenient to utilise some natural subdivision of the courses of the curriculum to mark off the subjects in which close supervision should be exercised from those in which the student should be encouraged to accustom himself to the apparent absence of higher control ; for there are few thing. so demoralising to the student as unequal treatment in the different departments which he has to attend in any one term.

The subsequent discussion of methods of education refers exclusively to the earlier subjects of the curriculum-viz., the subjects of the first and second professional examinations. Every teacher of these early subjects must have observed, with feelings akin to despair, the manner in which many students reduce their whole course of medical study to chaos by their failure to pass the subjects of their first professional examination, and failures are far more often due to inexperience than to laziness or real stupidity. In the present writer's opinion much of the difficulty experienced by students at the commencement of the curriculum is due to their failure to appreciate the importance and bearing of their practical work. To get practical work well done it is necessary to convince the student that the doing of it is worth while. A student's outlook is limited, and "worth while" to him means obviously worth while. "Obviously worth while" in turn means a direct help to him in getting through his examinations. Now it is impossible to train a student to observe for himself without making him do practical work, and it is not easy to devise an examination which will fairly test a student's power of observation and of doing practical work. It is easy, however, to discover a student's aptitude for these things by noticing his progress from day to day throughout the whole course in any one subject.

The daily work is the work that tells at an examination; but the student frequently does not realise this and wastes the most valuable part of his education. The whole level of medical education will be raised when the student is compelled fully to realise the importance of regular and diligent performance of practical work. There does not seem to be any way of doing this except by making the proper performance of practical work throughout whole courses an integral part of the professional examinations. To do so would be to introduce no new principle into medical educa. tion. Already attendance at courses is insisted on. All that is now required is to carry this principle further, and to make really diligent and regular study compulsorv. Not only is it advisable to make really diligent attendance at practical courses count as a part of the professional examinations, but diligent attendance at lecture classes should 
also count. Frequent written examinations do not diminish but intensify the educative value of lecture demonstrations, and are in themselves highly educative. Very short papers once a week are of the greatest possible value. They teach students to arrange their knowledge and to express themselves clearly, and their frequency prevents cramming. To keep abreast with them at all students have to work regularly. To teach regularity in work is one of the objects of a medical school. Alternating periods of idling and cramming are the result of occasional examinations. With weekly examinations, examination fever ceases to be a trouble, and a high uniform level of work is maintained. Even the examinations are robbed of their terror and become highly educative. There seems every reason to believe that to make the work done from day to day count towards a pass in the professional examination would do much to solve the problems that surround us. But the professional examination would require to be retained as a goal, and should be treated by the teacher as the grand revisal of the class" work. The utilisation of the results of the class work as an integral portion of the professional examination may be objected to as involving too close a supervision over the stadents. I must be remembered that it is only recommended by the present writer in the case of the subjects of the first and second professional examinations with which the present discussion is alone concerned.

With regard to the manner of instruction, and still dealing purely with the study of the normal, it may be said without hesitation that the set lecture illustrated by blackboard drawings and diagrams alone is an anachronism. Practical work is the essential thing; but as time is short and must be saved there must also be lecture demonstrations. It is almost useless to turn students loose in a laboratory to do something. They must be told what to do, and shown how to do it, then they must go and do it for themselves, and through it all the teacher must weave threads of connecting thought. To do this demands that the subjects studied are so arranged that the thought may grow naturally and easily, and above all, that regardless of departments, subjects are dealt with as a whole. For example, it should be impossible that a student should have described to him the macroscopic structure of the human heart one winter; the microscopic structure and something of the phylogenetic and ontogenetic history of the same organ at different parts of the next summer; the circulation of the blood and the function and sounds of the heart the following winter; that he should himself make a dissection of the organ the summer after that; and that he should be permitted to delay the successful demonstration of his understanding the principles of the construction of pumps until a date even subsequent to that again. At present in many schools he may do this, and the crowning absurdity is that before he has commenced his disjointed studies he may be working in the wards of a general hospital. Such a travesty of education should be impossible. The student has not time to waste. He should be helped in every possible way to acquire sufficient knowledge of the normal to enable him to understand the nature of disease and its treatment. To save time in the early years of the curriculum is to gain time for the study of the clinical subjects.

\section{SANITATION IN INDIA.}

\section{III. ${ }^{1}$}

Hospitals and Dispensaries (conoluded). Eastern Bengal and Assam.

Colonel R. Neil Campbell, I.M.S., furnishes the report for the hospitals and dispensaries of Eastern Bengal and Assam. On the last day of the year 1908 there were 522 of these institutions open. The total number of in-patients rose from 24,455 in 1907 to 26,246 in 1908 , and the outpatients numbered $3,245,167$, in comparison with $3,059,349$ for the previous year. The reasons given for the increase of the patients are the progressive popularity of the institutions and the unhealthiness of the localities, while in the case of Demagiri the admissions were increased by coolies imported for the construction of the roads from Demagiri to Lungleh.

The largest number of admissions was due to worms, this

Nos. I. and II. were published in Tes LANCET of May 7th (p. 1289) and 14 th (p. 1369) respectively. being 562,590 , or $17 \cdot 2$ per cent. of the total treated; the figures in 1907 were 507,304 , or 16.6 per cent. Malarial fevers and skin diseases come next. There were 201 cases of carcinoma and 173 of sarcoma. Dysentery, and especially cholera and diarrhœa, showed a marked decrease. Goitre was particularly prevalent in the Naga Hills, there having been 2590 cases. The surgical operations which were performed amounted to 77,363 , as compared with 76,366 in 1907. The operations included amongst others those for aneurysm, operations on the skull and brain, laparotomies, nephrotomy, and operations for stone (112).

Central Provinoes.

In the report for 1908 for the Central Provinces by Colonel P. A. Weir, I.M.S, we are informed that 269 dispensaries were at work, treating both indoor and outdoor patients to the number of $1,731,282$. The chief diseases were malarial fevers, skin diseases, ulcers, eye affections, and respiratory and digestive diseases. Malarial fevers headed the list. Cholera occurred in 17 districts, whilst dysentery and diarrhœa were more prevalent.

\section{Madras.}

The General Hospital, Madras, treated 52,243 out-patients and 7512 in-patients; the average of the latter was the highest of ten years, a marked increase being shown both amongst Europeans and non-Europeans. With regard to the former, the total number in the last ten years has been falling off, probably due to the fact that the private practitioners in Madras are yearly increasing in number. This would be more likely to affect the European than the nonEuropean population. 7396 operations were performed. Cholera was present in an epidemic form in Madras from August to October.

Coming now more particularly to the facts noted, Major C. Donovan, I.M.S., in his summary makes some interesting remarks on certain diseases In regard to malaria, his method of treatment is to give a single dose of 30 grains of quinine, with " the happiest result as far as the cure of the disease is concerned." He quotes a case in which three species of malarial parasites were present on the admission of the patient. After the dose of quinine he remained free for 19 days, when the temperature rose, but only one species was then found. After another 36 days of apyrexia a second relapse took place, when only a second species (a different one) was found. This would favour, in a way, Laveran's views that the parasite of malaria constitutes a single species with three varieties. A case of cerebral malaria is recorded; the patient was admitted moribund, and the cerebral capillaries were plugged too extensively to admit of relief. A case of blackwater fever is recorded in which quinine in two doses of 10 grains brought on the hæmoglobinuria ; and Major Donovan throws out the suggestion that the severe form of paludal fever is due to a distinct form of laverania, the parasites being of a peculiar shape.

Kala-azar gave rise to 59 admissions; the cases were all diagnosed except four by the detection of leishmania in the peripheral circulation; in one of the cases after death this organism was found in the solid viscera. This disease is very limited in the Presidency, being confined to the municipal boundaries of the corporation of Madras, and to Blacktown particularly. Major Donovan gives a succinct account of the history of the parasite and discusses its proper place in classification; he does not now locate it amongst the sporozoa. With regard to its transmission, he made observations by feeding bed bugs on kala-azar patients, but without success, and on searching for some other bloodsucking insect he came across a red and black bug which may possibly be a causative factor. In the treatment of the affection he has administered quinine by the mouth and by intramuscular injection, liquor arsenii et hydrargyri, both with and without vinum antimoniale, fuchsin, and thymol. The amelioration under fuchsin, which at first seemed to be satisfactory, proved only transient. One case, however, is narrated in which, 18 months after the treatment, the patient is in perfect health.

Major Donovan also relates a very interesting case in which he states he mis 'ook kala-azar for typhoid fever. A patient was suddenly taken ill with a continuous temperature of $104^{\circ} \mathrm{F}$. (more or less) for a week before admission. The temperature then remitted, and after 35 days came to normal by lysis exactly like typhoid fever. There were pink roseolæ, tympanites, right iliac gurgling, slight enlargement 